\title{
A Study of Fungal Septicaemia in New Born at Tertiary Care Hospital
}

\author{
Jitendra Kumar Chaudhary, Amit Kumar Singh*, \\ Shamsheer Ali Teeto and Hariom Sharan
}

Department of Microbiology, Varunarjun Medical College, Banthra, Shahjahanpur, India

*Corresponding author

\begin{tabular}{|l}
\hline K e y w o r d s \\
$\begin{array}{l}\text { Candida, Fungal } \\
\text { sepsis, Fungal blood } \\
\text { stream infection, } \\
\text { Neonates }\end{array}$ \\
\hline Article Info \\
\hline $\begin{array}{l}\text { Accepted: } \\
\text { 04 January } 2019 \\
\text { Available Online: } \\
\text { 10 February } 2019\end{array}$
\end{tabular}

\section{Introduction}

Candida species are a common cause of neonatal nosocomial bloodstream infections in infants and are a leading cause of infectious-related mortality in the neonatal intensive care unit (NICU) (1). Invasive candidiasis refers to systemic infection with Candida of either vital organs or normally sterile body fluid (blood, cerebrospinal fluid (CSF), or urine acquired by sterile catheterization or suprapubic aspiration). Significance of Candida spp in neonatal intensive care units (NICU) is increasingly being recognized. It is the third most common cause of late onset sepsis in NICU patients and accounts for 9 to $13 \%$ of blood serum infections (BSI) in neonates. ${ }^{1}$ Fungal sepsis should be suspected in a critically ill neonate with negative blood culture. ${ }^{2}$ Until recently, C. albicans was by far the predominant species in most countries, responsible for $60 \%$ of all cases of candidemia. However, recently several countries around the world have witnessed a change in the epidemiology of Candida infections, characterized by a progressive shift from a predominance of $C$. albicans to non-albicans Candida species 
notably C. tropicalis, C. parapsilosis, $C$. krusei, C. guilliermondii and C. glabrata. $^{3,4}$ This changing trend is a matter of concern due to the emerging resistance of the nonalbicans species to azoles. There is growing evidence suggesting a role of increasing use of azole agents in this epidemiological shift. Several of these NAC species exhibit intrinsic resistance to traditional triazoles like fluconazole (FLK) and may also demonstrate cross resistance to newer triazoles. ${ }^{5}$

The sources of candidiasis in NICU are often endogenous following colonization of babies with fungi. About $10 \%$ of these babies get colonized in the first week of life and up to $64 \%$ babies get colonized by 4 weeks of hospital stay. ${ }^{6}$ Administration of contaminated intravenous solutions, notably the solution for total parental nutrition (especially the intra-lipid) may result in NICU outbreaks. Spread may also occur from patient to patient or through a colonized health care worker. ${ }^{7-9}$

Apart from these a number of other factors including the use of indwelling devices, broad spectrum antibiotics, low birth weight (LBW), prematurity, gastrointestinal surgery, artificial ventilation, and/or history of fungal colonization contribute to the risk. ${ }^{10}$ Clinical presentation of candidemia resembles sepsis syndrome and to establish a clinical diagnosis is difficult. ${ }^{11,12}$ Signs of fungal sepsis include thrombocytopenia, lethargy, glucose instability, increasing ventilation requirement and apnoea.

End organ damage is more common and severe in systemic fungal infections and can involve the kidneys, joint, brain, lung, eyes, liver, spleen and bones. ${ }^{13,14}$. The renal manifestations can be in the form of acute renal failure, hypertension or flank masses. Endopthalmitis is a complication of invasive disease and needs urgent intervention. ${ }^{15}$
The objective of this study was to determine the different fungal pathogens, review their sensitivity patterns and clinical risk factors.

\section{Materials and Methods}

This retrospective study was conducted between May 2018 and October 2018 in a tertiary care NICU in our hospital. All newborn aged 0 to 28 days admitted in neonatal intensive care unit (NICU) from May 2018 to October 2018 in whom fungal organism was isolated in blood culture were recruited in the study. Empirical antibiotic used was retrieved from the study. Candidemia was defined as the presence of at least one positive blood culture containing pure growth of Candida spp. with supportive clinical features. Any growth indicated was sub-cultured on $5 \%$ sheep blood agar and Sabouraud's dextrose agar (SDA) with chloramphenicol $(0.05 \%)$ and incubated at $37^{\circ} \mathrm{C}$ for a minimum of 48 hours up to two weeks.

The Candida spp. isolated was identified as per standard mycological techniques. ${ }^{17}$ Preliminary identification was done by colony morphology on SDA, chromogenic media (Hichrome, Himedia Pvt. Ltd.), grown at $45^{\circ} \mathrm{C}$, germ tube test, chlamydospore formation, and was confirmed by carbohydrate fermentation and assimilation tests. ${ }^{17}$ Anti-Fungal sensitivity was performed for FLK (25 mg), and amphotericin B (AMB, 100 units) using disc diffusion method on Muller-Hinton agar supplemented with $2 \%$ glucose and methylene blue $(5 \mathrm{mg} / \mathrm{ml}){ }^{18,19}$ Zone diameters were interpreted as per the approved Clinical Laboratory Standards (CLSI) guidelines. Quality control for AFS was performed using $C$. albicans-ATCC 90028 and $C$. parapsilosis-ATCC $22019 .^{20}$

\section{Statistical analysis}

Statistical analysis was done using Statistical Package for Social Sciences (SPSS) version 
11 and the prevalence of organisms was determined and expressed in percentage.

\section{Results and Discussion}

Of the total 210 neonates included in the study fungal sepsis was found in (25/210) $11.9 \%$ of cases. NAC species were responsible for $85 \%$ of cases with C. glabrata $11(44 \%)$ as the most predominant species. Other species isolated were $C$. tropicalis 5 $(20 \%)$

C. albicans 4 (16\%), C. paraspinolosis 3 (12\%), C. krusei 1 (4\%) and C. kodo 1 (4\%) (Table 1). Antifungal sensitivity results revealed that most of the NAC isolates especially Candida glabrata, Candida paraspinolosis were resistant to fluconazole than Candida albicans. AMP showed more sensitivity than FLK over NAC species (Table 2). Among the risk factor observed for candidemia (Table 3) were LBW, prematurity, prolonged antibiotic use, ventilator support and TPN as described below in Tables 3-4.

Table.1 Isolated candida species on the basis of culture and LPCB $(n=25)$

\begin{tabular}{|l|l|l|}
\hline Organism & No of isolates & $\%$ \\
\hline Candida glabrata & 11 & 44 \\
\hline Candida tropicalis & 5 & 20 \\
\hline Candida albicans & 4 & 16 \\
\hline $\begin{array}{l}\text { Candida } \\
\text { parapselosis }\end{array}$ & 3 & 12 \\
\hline Candida Krusei & 1 & 4 \\
\hline Candida Kodo & 1 & 4 \\
\hline
\end{tabular}

Table.2 Anti-fungal susceptibility profile of Candida isolates $(\mathrm{n}=25)$

\begin{tabular}{|l|l|l|l|l|l|l|}
\hline S.No & Organism & FLK* n & $(\boldsymbol{\%})$ & AMB** n & $(\boldsymbol{\%})$ & $\begin{array}{l}\text { Total no. } \\
\text { of } \\
\text { isolates }\end{array}$ \\
\hline $\mathbf{1}$ & Candida glabrata & 3 & 27.3 & 9 & 81.8 & 11 \\
\hline $\mathbf{2}$ & Candida tropicalis & 3 & 60 & 5 & 100 & 5 \\
\hline $\mathbf{3}$ & Candida albicans & 3 & 75 & 4 & 100 & 4 \\
\hline $\mathbf{4}$ & Candida paraspinolosis & 2 & 66.7 & 3 & 100 & 3 \\
\hline $\mathbf{5}$ & Candida krusei & 0 & 0 & 1 & 100 & 1 \\
\hline $\mathbf{6}$ & Candida kodo & 1 & 100 & 1 & 100 & 1 \\
\hline
\end{tabular}

FLK* - Fluconazole; AMB** - Amphotericin B.

Table.3 Potential risk factor for candidemia among neonates $(\mathrm{n}=25)$

\begin{tabular}{|l|l|l|l|l|}
\hline & Frequency & $\mathbf{( \% )}$ & Valid \% & Cumulative (\%) \\
\hline$<1 \mathbf{~ k g}$ & 5 & 20 & 20 & 20 \\
\hline $\mathbf{1 - 1 . 5} \mathbf{~ k g}$ & 6 & 24 & 24 & 44 \\
\hline $\mathbf{1 . 6 - 2 . 5} \mathbf{~ k g}$ & 5 & 20 & 20 & 64 \\
\hline$>\mathbf{2 . 5} \mathbf{~ k g}$ & 9 & 36 & 36 & 100 \\
\hline Total & 25 & 1000 & 100 & \\
\hline
\end{tabular}


Table.4 Ventilator support among candidemia neonates $(n=25)$

\begin{tabular}{|l|l|l|l|l|}
\hline & Frequency & $\mathbf{( \% )}$ & $\mathbf{( \% )}$ & Cumulative \\
\hline <7days & 2 & 8 & 8 & 8 \\
\hline 7-14 days & 4 & 16 & 16 & 24 \\
\hline >14 days & 14 & 24 & 24 & 48 \\
\hline Not used & 13 & 52 & 52 & 100 \\
\hline Total & 25 & 100 & 100 & \\
\hline
\end{tabular}

Fungal BSI is an important cause of morbidity and mortality in sick newborn infants. In the present study, isolation rate observed was $11.9 \%$. This was comparable with study conducted by Rani et al., where isolation rate was $11 \% .^{21,22}$

Of the total cases of neonatal candidemia, NAC species accounted for $85 \%$ of the cases, whereas $C$. albicans was responsible for $15 \%$ of cases. This corroborates well with the results of other authors23. Striking feature of the present study was isolation of $C$. glabrata $(44 \%)$ as the most predominant NAC species followed by C. tropicalis (20\%).

In recent years, there is marked shift in isolation rates of non-albicans Candida species compared to Candida albicans in cases of neonatal sepsis. Kossoff et al. ${ }^{24}$ showed significant shift from Candida albicans to non-albicans, i.e. Candida parapsilosis over 15 years. Rani et al., observed Candida tropicalis as predominant pathogen (92\%), followed by Candida albicans and Candida kefyr (4\% each). ${ }^{24}$ All these findings are in contrast to present study which showed that Candida glabrata is emerging as predominant cause of neonatal sepsis.

This is in accordance with Karen et al., which showed Candida glabrata as emerging pathogen. ${ }^{25}$ Historically, Candida glabrata has been considered to be relatively nonpathogenic saprophyte of normal flora of healthy individuals rarely causing serious infections. ${ }^{26}$ However, following widespread and increased use of immunosuppressive therapy, broad spectrum antibiotic therapy, increased conditions causing compromise of the immune system, the frequency of mucosal as well as systemic infections caused by Candida glabrata has increased significantly. ${ }^{22,27}$

Though Candida glabrata has emerged as important nosocomial pathogen, yet little is known about its epidemiology. ${ }^{26}$ Infection with this species is associated with highmortality rate. ${ }^{25,26}$ Candida glabrata is of special importance because of its innately increased resistance to antifungal drugs, especially azoles. ${ }^{25,26}$ The reasons behind emergence of the species as predominant pathogen could be because of selection of lesser susceptible species due to frequent use of fluconazole as prophylaxis. ${ }^{27}$

C. tropicalis causes infections with high mortality in adults and children with hematological malignancies or in immunecompromised individuals. ${ }^{28}$ Ability of this organism to produce clusters is one of its major virulence factors. Once introduced into the immune-compromised host, $C$. tropicalis may be more virulent than $C$. albicans and can rapidly progress from colonization to invasion. It is the second leading cause of candidemia in adults, but is quite infrequent among neonates. ${ }^{28}$ In the present study, $C$. glabrata and C. tropicalis have emerged as predominant species accounting for $72 \%$ of infected neonates. 
AFS results showed that $27 \%$ of $C$. glabrata species were sensitive to FLK. High degree of resistance to azole compounds among $C$. glabrata species has been seen in many reports and can vary from $3.6 \%$ to $64 \%$. $^{29,30}$ Resistance to AMB noted to be $19 \%$ is a matter of concern as emergence of such isolates may pose serious therapeutic challenges and also increases risk of nosocomial infection.

Combination of various risk factors is known to be strongly associated with development of candidemia. The major risk factors identified in our study were prematurity (60\%), low birth weight $(60 \%)$, prolonged antibiotic use $(60 \%)$, ventilator support $(56 \%)$ and total parenteral nutrition $(50 \%)$.

Most of the neonates positive for candidemia were premature or low birth weight. This is in close agreement with many other reports. ${ }^{23}$ Mechanical ventilation has well been described as a risk factor for the development of neonatal fungal blood stream infection. In present study, mechanical ventilation has a strong association for development of candidiasis in NICU admitted neonates than other studies. ${ }^{23}$ Broad spectrum antibiotics were being administered to most of the neonates in the present study. They promote fungal overgrowth at the expense of normal bacterial flora and encourage translocation of yeast across the intact mucosa.

The risk of candidemia is known to increase exponentially with each class of antimicrobial used. Long term use of these broad-spectrum antibiotics must have created a negative pressure and favorable environment for Candida spp. to flourish. This substantiates the need of prophylactic antifungal to be used in a set up where continuous upsurge in the incidence of candidemia is seen.

In conclusion, fungal BSI is an important problem in neonates with a high mortality rate and significant incidence of resistant organisms. Reporting of fungal BSI and the spectrum of species involved are essential measures in any ICU in order to implement appropriate preventive and therapeutic strategies. Antifungal susceptibility is very essential for effective treatment and the authors have also done susceptibility testing of their Candida isolates by disc diffusion test. Minimum inhibitory concentration (MIC) determination as per Clinical and Laboratory Standards Institute (CLSI) M27-A3 guidelines may be more reliable in such circumstances as also increasing the number of antifungals to include newer azoles (like ravuconazole, posaconazole) and echinocandins, as often some isolates are multidrug resistant (resistant across two antifungal classes). For echinocandins, disk diffusion is not recommended by CLSI.

As breakpoint MICs for some newer Candida species is still not defined by CLSI M27- A3, breakpoint suggested for yeast in CLSI M27S4 can be used for such interpretations. Preventive measures such as use of filters for TPN, prophylactic antifungal use, and a restrictive policy of antibiotic use to decrease Candida colonization infection rates should be implemented to decrease mortality and morbidity associated with these infections. Also, previously ignored, NAC species esp Candida glabrata received little attention; therefore, not surprisingly our knowledge regarding them is not only incomplete, but also significantly lacking. So, we now need to have more studies and more tools; specially molecular tools to study the epidemiology of this emerging problem. Understanding the mechanisms of innate and acquired resistance may facilitate development of new targets for antifungal agents. Mechanical ventilation had well been described the risk factors played a significant role for the development of neonatal fungal blood stream infection as it is showed by the present study. 


\section{References}

1. Benjamin DK, Stoll BJ, Fanaroff AA, McDonald SA, Oh W, Higgins RD, et al., Neonatal candidiasis among extremely low birth weight infants: risk factors, mortality rates, and neurodevelopmental outcomes at 18 to 22 months. Pediatr. 2006; 117(1): 84-92.

2. Baley JE. Neonatal candidiasis: the current challenge. Clin Perinatol. 1991; 18(2): 263-80.

3. Goel N, Ranjan PK, Aggarwal R, Chaudhary U, Sanjeev N. Emergence of non albicans Candida in neonatal septicemia and antifungal susceptibility: Experience from a reference tertiary care center. J Lab Physicians. 2009; 1(2): 53-5.

4. Oberoi JK, Wattal C, Goel N, Raveendran R, Datta S, Prasad K. Non-albicans Candida species in blood stream infections in a tertiary care hospital at New Delhi, India. Indian J Med Res. 2012; 136(6): 997-1003.

5. Magill SS, Shields C, Sears CL, Choti M, Merz WG. Triazole cross-resistance among Candida spp.: Case report, occurrence among bloodstream isolates, and implications for antifungal therapy. $\mathbf{J}$ Clin Microbiol. 2006; 44: 529-35.

6. Huang YC, Li CC, Liu TY, Lien RI, Chou $\mathrm{YH}, \mathrm{Wu} \mathrm{JL}$, et al., Association of fungal colonization and invasive disease in very low birth weight infants. Paediatr Infect Dis J. 1992; 17: 819-22.

7. Robertson NR. Neonatal infections. In Robertson Textbook of Neonatology, 2nd edn. Churchill Living Stone; 1992: 984-5.

8. Baley JE, Kliegman RM, Fanaroff AA. Disseminated fungal infections in very; low birth weight infants: clinical manifestations and epidemiology. Pediatr. 1992; 73: 144-52.

9. Libovitz E. Neonatal candidiasis: clinical picture, management controversies and consensus and new therapeutic options. J
Antimicrobial Chemother. 2002; 49: 6973.

10. Singhi S, Rao DS, Chakrabarti A. Candida colonization and candidemia in a pediatric intensive care unit. Pediatr Crit Care Med. 2008; 9: 91-5.

11. Ariff S, Saleem AF, Soofi SB, Sajjad R. Clinical spectrum and outcomes of neonatal candidiasis in a tertiary care hospital in Karachi, Pakistan. J Infect Dev Ctries. 2011; 5: 216-23.

12. Zaoutis TE, Prasad PA, Localio AR, Coffin SE, Bell LM, Walsh TJ, et al., Risk factors and predictors for candidemia in pediatric intensive care unit patients: Implications for prevention. Clin Infect Dis. 2010; 51: 38-45.

13. Benjamin DK, Ross K, McKinney RE, Benjamin DK, Auten R. When to suspect fungal infection in neonates: a clinical comparison of Candida albicans and Candida paraspilosis fungemia with coagulase - negative staphylococcal bacterimia. Paediatr. 2000: 106: 712-8.

14. Kler N, Garg P. Fungal sepsis. Bull Nat Neonatol Forum. 1999; 13: 13-5.

15. Davis LE. Fungal infections of the central nervous system. Neurol Clin. 1999; 17: 761.

16. Gudlaugsson O, Gillespie S, Lee K, Vande Berg J, Hu J, Messer S, et al., Attributable mortality of nosocomial candidemia, revisited. Clin Infect Dis. 2003; 37: 1172-7.

17. McGinnis MR. Laboratory Handbook of Medical Mycology. New York: Academic Press. Yeast Identification; 1980: 337-73.

18. Barry AL, Brown SD. Fluconazole disk diffusion procedure for determining susceptibility of Candida species. J Clin Microbiol. 1996; 34: 2154-7.

19. Kirkpatrick WR, Turner TM, Fothergill AW, McCarthy DI, Redding SW, Rinaldi MG, et al., Fluconazole disk diffusion susceptibility testing of Candida species. J Clin Microbiol. 1998; 36: 3429-32. 
20. Pennysylvania, USA. Clinical Laboratory and Standards Institutes. Performance standards for antimicrobial susceptibility testings; twenty first informational supplement; 2011:100-S21.

21. Agarwal J, Bansal S, Malik GK, Jain A. Trends in neonatal septicemia: Emergence of non-albicans Candida. Indian Pediatr. 2004; 41: 712-5.

22. Rani R, Mohapatra NP, Mehta G, Randhawa VS. Changing trends of Candida species in neonatal septicemia in a tertiary north Indian hospital. Indian J Med Microbiol. 2002; 20: 42-4.

23. Sardana V, Pandey A, Madan M, Goel SP, Asthana AK. Neonatal candidemia: a changing trend. Indian J Pathol Microbiol. 2012; 55: 132-3.

24. Kossoff EH, Buescher ES, Karlowicz MG. Candidemia in a neonatal intensive care unit: Trends during fifteen years and clinical features of 111 cases. Pediatr Infect Dis J. 1998; 17: 504-8.

25. Karen DF, Smita T, Erica S, Fernando MV. Neonatal Candida glabrata sepsis: Clinical and laboratory features compared with other Candida species. Pediatr Infect Dis J. 2002; 22: 39-43.

26. Paul LF, Vanquez JA, Sobel JD. Candida glabrata: Review of epidemiology, pathogenesis and clinical disease with comparison to C. albicans. Clin Microbiol Rev. 1999; 12: 80-96.

27. Rinaldi M, Marr KA. Clinical significance of azole antifungal drug cross resistance in Canduda glabrata. J Clin Microbiol. 2006; 44: 1740-3.

28. Roilides E, Farmaki E, Evdoridou J, Francesconi A, Kasai M, Filioti J, et al., Candida tropicalis in a neonatal intensive care unit: Epidemiologic and molecular analysis of an outbreak of infection with an uncommon neonatal pathogen. J Clin Microbiol. 2003; 41: 735-41.

29. Sobel JD, Zervos M, Reed BD, Hooton T, Soper D, Nyirjesy P, et al., Fluconazole susceptibility of vaginal isolates obtained from women with complicated Candida vaginitis: Clinical implications. Antimicrob Agents Chemother. 2003; 47: 34-8.

30. Tseng $\mathrm{Y}$, Lee $\mathrm{W}$, Kuo $\mathrm{T}$. In-Vitro susceptibility of fluconazole and amphotericin B against Candida isolates from women with Vaginal Candidiasis in Taiwan. J Food Drug Anal. 2005; 13: 126.

\section{How to cite this article:}

Jitendra Kumar Chaudhary, Amit Kumar Singh, Shamsheer Ali Teeto and Hariom Sharan. A Study of Fungal Septicaemia in New Born at Tertiary Care Hospital. Int.J.Curr.Microbiol.App.Sci. 8(02): 342-348. doi: https://doi.org/10.20546/ijcmas.2019.802.039 